\title{
PANELA MINEIRA DE PEDRA SABÃO: ASPECTOS HISTÓRICOS, DA CULTURA MATERIAL E DESIGN
}

Maria Regina Álvares Correia Dias

UEMG - Universidade do Estado de Minas Gerais

regina.alvares@gmail.com

Victória Carolina Pinheiro Lopes

UEMG - Universidade do Estado de Minas Gerais

regina.alvares@gmail.com

Rosemary Bom Conselho Sales

UEMG - Universidade do Estado de Minas Gerais

rosebcs@gmail.com

Resumo: O presente trabalho é parte de um projeto de pesquisa institucional dedicado ao estudo das panelas fabricadas em Minas Gerais, se estendendo a produtos nacionais e internacionais. O propósito inicial foi verificar as questões relacionadas ao design, usabilidade e ergonomia das panelas, com vistas a melhorar a qualidade e eficiência dos produtos fabricados em Minas. Contudo, outros aspectos vieram à tona durante o desenvolvimento, que ampliaram a perspectiva de uma um estudo meramente experimental para um estudo histórico e antropológico. Nesse sentido destacam-se as panelas tradicionalmente "mineiras" fabricadas de ferro fundido e de pedra sabão. Ambos são artefatos de longa data, a primeira já é conhecida desde a idade do Ferro e a de pedra sabão, encontrada em escavações na região de Ouro Preto, datada de 2.000 a.C. Por sua característica única e territorial, busca-se com essa discussão mostrar as potencialidades de pesquisas em design relacionas a um artefato simples do dia a dia da sociedade, mas que merece ainda muita atenção por parte dos designers.

Palavras-chave: design, panelas, pedra sabão, cultura material, Minas Gerais

Abstract: The presente work is part of an institutional research project devoted to the study of the pans produced in Minas Gerais, extending the produtcs national and international. The initial purpose was to check the issues related to the design, usability and ergonomics of the pans with a view to improve the quality and efficiency of products made in Minas Gerais. However, other aspects came to light during development, which increased the prospect of a purely experimental study for a study historical and anthropological study. In this sense there are the traditional pots "mimeiras" made of cast iron and soapstone. Both are long-time artifacts, 
the first has been known since the age of iron and soap stone, found in excavations in the region of Minas Gerais in Grande Abrigo de Santana do Riacho, dated 2000 BC For its unique and territorial feature is sought with this discussion show the research potential related to design a simple artifact of everyday life of society, but it still deserves a lot of attention from designers.

Keywords: design, pans, soapstone, material culture, Minas Gerais

\section{INTRODUÇÃO}

O homem e o artefato constituem um par inseparável que caminham em uma dupla evolução. A presença dos objetos se dá em inúmeras situações da atividade humana, nas esferas biológica, psicológica e social. A necessidade da subsistência e de deslocamento foram desafiadores para a busca constante por ideias na esfera da materialidade pelo ser humano. Ao longo da história, o homem sempre buscou desenvolver artefatos e soluções a partir das suas necessidades, na evolução dos recipientes com finalidade culinária não foi diferente.

A produção de artefatos resulta da capacidade do homem de transformar a natureza e seu conjunto constitui a cultura material de um grupo social. Para Cardoso (1998), a cultura material possibilita o melhor entendimento dos artefatos produzidos e consumidos, bem como a maneira como eles se encaixam em sistemas simbólicos e ideológicos mais amplos.

Da necessidade básica da alimentação, o homem buscou inúmeras formas de manipular e preparar seus alimentos, cada qual com seu método; cru, assado, cozido, entre outros. Como forma de tecnologia, entretanto, ferver e cozer alimentos num líquido revolucionou a alimentação. De início, para obter essa proeza, somente habitando próximo às fontes geotérmicas, seja na Islândia, Japão e Nova Zelândia, onde a população preparava os alimentos dentre de sacos de linhos, pendurados dentro da água até seu cozimento, conforme narra Wilson (2014). Outra forma encontrada foi o emprego do próprio envoltório natural para o cozimento, como os moluscos, répteis e tartarugas. As cabaças vegetais, os talos côncavos de bambu também serviram de recipientes, assim com o estômago dos animais, que pela característica impermeável à água e certa resistência ao calor, serviu de recipiente para cozer. Outro método adotado foi o cozimento com pedras quentes, praticado em todo o planeta, há pelo menos 30 mil anos atrás. Consiste de uma espécie de forno subterrâneo, cavado no chão e revestido de pedras para deixá-lo impermeável. As pedras para cozinhar eram aquecidas no fogo e transferidas para o fosso e à medida que a temperatura baixava, novas pedras aquecidas eram colocadas até o término do preparo.

O cozimento com pedras aquecidas não durou muito depois do aparecimento da cerâmica que marcou uma etapa tecnológica importante na cultura humana. Não se sabe quando foi feito o primeiro vaso de cerâmica, mas já se tornou comum por volta de 10.000 a.C., especialmente na América do Sul, África e Japão. Antes utilizados somente para armazenar mantimentos e líquidos, os recipientes de cerâmica foram utilizados para cozimento com os gregos de Franchti em 3.000 a.C. que faziam caldeirões, caçarolas e frigideiras. A panela de cerâmica alterou totalmente a natureza 
da culinária, O preparo do mingau, o guisado e o cozimento de tubérculos como a mandioca, somente foi possíveis após o aparecimento da panela.

A panela sobreviveu ao tempo e revolucionou a alimentação humana, permitindo cozinhar uma quantidade maior de alimento imerso em água. A busca do homem em encontrar materiais disponíveis em seu ambiente para a confecção de utensílios culinários é remota como já comentado, podendo-se destacar também o empregado da pedra, seguida pela cerâmica e depois os metais. A preocupação com as melhorias das características sensoriais e sanitárias dos alimentos, somados à praticidade, estética, inocuidade dos materiais e sua disponibilidade contribuem para a busca contínua por novos materiais, como exposto por Quintaes (2005).

\section{PANELAS E MATERIAIS}

Verifica-se no mercado dos produtos voltados para a culinária o desenvolvimento crescente de novos materiais e novos processos de fabricação. Esse fenômeno se dá não somente para atender ao crescente número de profissionais formados atuantes na área da gastronomia, como também ao consumidor doméstico. No Brasil, nos últimos anos, o estilo de vida em apartamentos e condomínios residenciais alterou consideravelmente a demanda e o acesso a equipamentos e utensílios de melhor qualidade, sejam nacionais e importados.

Em relação ao revestimento das panelas, especialmente o interno que mantém contato com o alimento, novas tecnologias podem ser citadas, como (a) a descoberta de um revestimento antiaderente para panelas em 1938 chegou às cozinhas americanas na década de 60 . Trata-se de uma espécie de revestimento antiaderente na forma de uma película polimérica que reduz ou elimina a necessidade de óleo ao cozinhar. Muitas marcas são conhecidas dos consumidores, Teflon ${ }^{\circledR}$, marca registrada da DuPont, o T-Fal, entre outros; (b) o desenvolvimento de revestimentos cerâmicos de alta tecnologia também está em alta aplicação nas panelas, muitos com características antiaderentes, antibacteriano e menos agressivos à saúde em relação aos polímeros. Pode-se citar o Ecolon da empresa Neoflam, o Pro-ceramic desenvolvida pela empresa nacional Brinox; (c) o Silargan desenvolvido pela empresa Silit, feito de aço ferromagnético fundido com erâmica de alta tecnologia, possui propriedade antibacteriana, resistência a cortes e arranhões; (d) o Polywood da Tramontina, termoplástico composto de fibra natural possui excelente resistência para cabos de panelas e de facas, possui também ação antibacteriana; (e) as camadas das paredes, antes de um só material, passam a ter três e até cinco multicamadas, podendo citas a tecnologia SIGMA da Zwilling de aço inox e alumínio no miolo, de 3 a 5 camadas de materiais diferentes; as multicamadas da panela de cobre da Tramontina (cobre + alumínio + aço inox), dentre outras.

As panelas com fundo triplo são feitas com duas camadas de aço inox, envolvendo uma camada de alumínio que por ser melhor condutor que o aço inox distribui o calor da chama de maneira mais uniforme, facilitando o cozimento dos alimentos. Se o alumínio for substituído por cobre, o aquecimento ainda é mais homogêneo e rápido em toda sua superfície interna. A fixação do fundo difusor (aço + alumínio + aço) é feita através de uma pressão de impacto de até 3.000 toneladas. Este fundo aumenta significativamente a durabilidade e a resistência à corrosão e permite importantes economias de tempo e energia no cozimento dos alimentos. $\mathrm{O}$ sistema elimina o uso da solda tradicional que, por mais que as camadas sejam agregadas, 
sempre deixa pontos vulneráveis. Este processo de encapsulamento permite igualmente que o alumínio do fundo térmico fique totalmente envolvido pelo aço inoxidável, eliminando o risco da sua deterioração pelo uso ou lavagem e impossibilita a acumulação de resíduos entre a peça e o fundo térmico.

\subsection{Vantagens e desvantagens dos materiais}

Constata-se a existência de diversos materiais adequados, o que depende da disponibilidade geográfica, do tipo de alimentos e de sua preparação, bem como dos fatores culturais das populações. Outro fator relevante é considerar a interação de determinados alimentos com os materiais das panelas. Quintaes (2005) ressalta que determinados materiais são benéficos, outros são inócuos por não apresentar nenhuma alteração positiva ou negativa, e outros são maléficos à saúde.

Wilson (2014) relata que o engenheiro americano Chuck Lemme (1988) examinou diferentes materiais disponíveis naquela época, para estabeleceu nove categorias de análise para se obter a "panela ideal". Os pontos são:
1. Uniformidade da temperatura;
2. Toxidade e reatividade;
3. Dureza;
4. Resistência a quedas;
5. Aderência da superfície;
6. Facilidade de manutenção e limpeza;
7. Eficiência energética;
8. Peso;
9. Preço.

Em cada categoria Lemme (1988) atribuiu notas aos materiais, num total de dez, totalizando em 1.000 a panela com maior "grau de idealidade". Ao final da análise, concluiu-se que seria difícil chegar ao ideal, uma vez que o conjunto dos requisitos deveria ser equilibrado. Por exemplo, uma panela de cobre obteve nota 10 para eficiência, mas recebeu 1 na manutenção e limpeza. A panela de alumínio obteve nota alta para uniformidade de temperatura 8,9 , mas no quesito dureza obteve 2 . A panela melhor avaliada foi a de ferro fundido, obtendo 544 em 1.000, o que é ainda muito baixa. Deve-se ressaltar que a tecnologia de camadas de metais, relatada no item anterior tem possibilitado uma maior qualidade das panelas nos tempos atuais. 0 mesmo autor chama atenção para o fato de um único material ser quase impossível para atender a tantos atributos divergentes, mas um "conjunto de materiais" ideiais tem sido perseguido.

É importante, portanto, considerar estes fatores de forma conjunta ao selecionar as panelas em relação ao seu uso particular. Contudo, os consumidores finais são geralmente pouco informados sobre o papel dos utensílios culinários na saúde humana, exceto pelo conhecimento popular ou mesmo aquele adquirido com a prática do dia-a-dia.

\subsection{Materiais e nutrição}

A Interação entre alimentos e utensílios pode ser benéfica, inócua ou prejudicial (QUINTAES, 2005, p. 11). Segundo critérios de saúde e nutrição, não há um material que possa ser considerado melhor ou ideal para o preparo de alimentos em 
todos os aspectos. "O material ideal para contato com alimentos vai depender da composição do alimento a ser preparado, das condições físicas de contato, das necessidades nutricionais do consumidor, entre outros fatores" (QUINTAES, 2005, p. 12). No entanto, a autora ressalta que existem poucos estudos sobre materiais na fabricação de utensílios domésticos, o que gera falta de informação para os consumidores finais. Cada material apresenta uma interação diferente com determinado alimento, influenciando a saúde humana de alguma forma, essa influência tem sido objeto de estudo de várias pesquisas.

As normas e regulamentos brasileiros que se aplicam aos materiais, fabricação e utilização das panelas são procedentes da ABNT, Inmetro e Anvisa. A ABNT normaliza as especificações dos metais e ligas, composição química, especificação geométrica dos produtos, tratamentos de superfícies, os utensílios domésticos metálicos para forno e fogão, os métodos ensaios. A ISO normaliza a aplicação dos revestimentos vítreos (esmaltação) e respectivos métodos de ensaios. O Inmetro regulamenta os requisitos técnicos para garantir a qualidade de panelas de pressão e panelas metálicas, visando a prevenção de acidentes. A Anvisa regulamenta o uso de elastômeros, metais e plásticos em contato com alimentos. Em relação a panelas, a Anvisa regulamenta os metais internos, vidro, revestimento antiaderente polimérico.

Pesquisas realizadas por Quintaes $(2004,2005)$ fornecem subsídios tanto para a regulamentação do uso dos materiais, como para orientação em relação ao uso e manejo do utensílio por parte dos usuários.

\begin{tabular}{|c|c|}
\hline CARACTERÍSTICA DO USUÁRIO & INDICAÇÃO DO MATERIAL DA PANELA \\
\hline $\begin{array}{l}\text { CRIANÇAS A PARTIR DOS } 6 \\
\text { MESES DE IDADE }\end{array}$ & $\begin{array}{l}\text { Panela de ferro, panela esmaltada nova, } \\
\text { panela inox usada, panela de vidro, } \\
\text { panela de cerâmica nova }\end{array}$ \\
\hline GESTANTES E NUTRIZES & $\begin{array}{l}\text { Panela de ferro, panela esmaltada, } \\
\text { panela de inox usada, panela de vidro, } \\
\text { panela de cerâmica, panela de barro, } \\
\text { panela de pedra sabão. }\end{array}$ \\
\hline ADOLESCENTES & $\begin{array}{l}\text { Panela de ferro, panela de esmaltada } \\
\text { nova, panela de inox usada, panela de } \\
\text { vidro, panela de cerâmica nova, panela } \\
\text { de barro. }\end{array}$ \\
\hline IDOSOS & $\begin{array}{l}\text { Panela de ferro, panela de esmaltada } \\
\text { nova, panela de inox usada, panela de } \\
\text { vidro, panela de cerâmica nova, panela } \\
\text { de barro, panela de cobre. }\end{array}$ \\
\hline ANÊMICOS & $\begin{array}{l}\text { Panela de ferro, panela de inox usada, } \\
\text { panela de pedra sabão. }\end{array}$ \\
\hline
\end{tabular}

Figura 2: Indicação de diferentes materiais para panelas segundo características dos usuários Fonte: Quintaes, 2005, p. 125

\section{PANELA DE PEDRA SABÃO}

Em Minas Gerais são três os materiais mais empregados na fabricação de panelas e utensílios para a coç̧ão de alimentos: o ferro, alumínio e pedra-sabão. Os dois primeiros são produzidos à partes da técnica tradicional da fundição de metais, o qual o material é derretido em seu estado líquido e colocado em moldes que permitem a conformação do produto que quando retorna à temperatura desejada, 
adquire a forma final da panela. No caso da pedra-sabão, as panelas são conformadas pelo processo do torneamento - processo artesanal e semi-industrial - que permite que um bloco sólido da pedra seja cavado internamente e modelado externamente. Vale ressaltar que a culinária mineira é uma tradição consolidada, seja no cozimento em fogão e forno de lenha, ainda amplamente utilizados, na escolha dos utensílios em geral e na maneira peculiar de preparar os tradicionais pratos salgados, compotas, doces caseiros, biscoitos e pães.

O esteatito, rocha que devido à pequena dureza era empregada na confeç̧ão de artefatos, foi provavelmente uma das primeiras matérias primas usada para produção de recipientes para uso culinário (QUINTAES, 2004, p. 16). É o único tipo de pedra natural que pode ser utilizada como recipiente com propósito culinário, devido as suas características físicas e químicas. O material é abundância na região do quadrilátero ferrífero, localizada no estado de Minas Gerais. Apesar de possuir aplicações industriais, o esteatito é tradicionalmente utilizado na produção de utensílios culinários comumente conhecidos como panelas de pedra sabão.

\subsection{História do artefato}

Vasilhas de pedra sabão vêm sendo produzidas e utilizadas em Minas Gerais desde 2000 a.C sendo reconhecidas hoje como artigos da indústria e comércio cultural, representativos de uma identidade mineira fortemente ligada ao período Barroco. Sua ocorrência em sítios arqueológicos e museus, bem como o volume, o alcance de sua produção e comércio atual, chamam a atenção para a importância destes artefatos na história de Minas. Apesar disso evidencia-se a falta de estudos quem contemplem esta categoria de artefatos, levando a uma grande confusão no que se refere às informações sobre as vasilhas de pedra sabão, instituindo inclusive uma memória forjada (MELQUIADES, 2012, p. 11).

A incipiência nos estudos que tratam esta categoria de artefato culminou na forja da memória de pedra sabão em Minas Gerais, onde não foram consideradas informações, sobre os atores, saberes e peculiaridades que compõe este coletivo, ocultando a contribuição deste no contexto cultural histórico. Melquiades (2012) propõe um estudo sobre os aspectos das relações vividas pelas vasilhas de pedra sabão em Minas Gerais no decorrer dos períodos históricos dos séculos (XIII e XXI) lançando um novo e primeiro olhar, sobre essa categoria de artefato até então não contemplados enquanto objetos centrais, em estudos arqueológicos, historiográficos e ou/ antropológicos. $\mathrm{O}$ autor ainda ressalta que, quase nenhuma referência a vasilhas de pedra sabão foram encontrados na literatura arqueológica. Da pouca bibliografia disponível referente a vasilhas de pedra sabão, foram encontradas em pouquíssimos textos relacionados a grupos indígenas pré-coloniais (JUNQUEIRA, 1984; WUST, 1990; PROUS E MALTA, 1991; PROUS, 1992).

Há presença de sítios arqueológicos indígenas pré-coloniais no holoceno mineiro. No grande abrigo de Santana do Riacho (situado na Serra do Cipó) foram encontrados fragmentos de potes de pedra sabão, a camada encontrada foi datada entre 2.800 a 4.500 a.C. (JUNQUEIRA, 1984; PROUS E MALTA, 1991). Já do período colonial e imperial, já acervo com uma série de coleções oriundas de sítios arqueológicos, doações ou aquisições, hoje presente em museus e instituições de pesquisa. Segundo Melquiades (2012) há uma delimitação temporal que vai desde o 
século II a.C, a atualidade havendo, no entanto necessidade de ser vista e não, ao menos inicialmente de forma unidirecional ou continua.

O uso das panelas de pedra sabão é forte na tradição mineira. As principais jazidas e os pólos históricos desta produção artesanal se situam em pequenos distritos, nos arredores das cidades históricas, de Ouro Preto, Mariana, Congonhas (Santa Rita de Ouro Preto e Cachoeira do Brumado) nestas comunidades as panelas de pedra sabão vêm sendo produzidas e utilizadas desde o século XVIII.

Melquiades (2012) constata a necessidade de levantamento e sistematização de informações a cerca das vasilhas de pedra sabão, e indaga porque os artesãos não são considerados nos museus ou em políticas públicas de gestão do patrimônio. Se há uma produção atual, então a aproximação das comunidades com as políticas de proteção e incentivo ao patrimônio cultural tem altíssimo potencial em gerar uma melhoria na qualidade de vida desses artesãos.

\subsection{Produção artesanal e uso}

As panelas de pedra sabão são produzidas e amplamente utilizadas no estado de Minas gerais a sua produção também abastece aos mercados, nacional e internacional. Na fase inicial do projeto "Estudo de panelas fabricadas em Minas Gerais" foram mapeadas 62 empresas fabricantes de panelas no estado.

Segundo Quintaes (2004) cerca de $81 \%$ dos habitantes nativos da região de Ouro Preto (MG) possuem panelas de pedra-sabão e $79 \%$ usam com regularidade.

Tradicionalmente, para fabricar uma panela em pedra sabão, utiliza-se uma pedra pré-formada, fixada em um torno mecânico horizontal. O torno roda a pedra, que é cavada internamente e modelada externamente de acordo com diferentes modelos e diâmetros. Cada panela recebe em seguida a própria tampa, feita de um disco também pré-formado e adaptado exatamente à boca da panela. Algumas empresas utilizam tornos semiautomáticos que permitem uma produção mais rápida, eficiente e padronizada com um melhor acabamento. Contudo, o método conhecido desde a Idade Média requer a habilidade manual de experientes artesãos. A maioria dos produtores de panelas de pedra é artesanal e de pequeno porte. Os modelos são praticamente os mesmos, com pequenas variações nos sistemas de pegas com diferentes materiais.

É conhecido pela população mineira que as panelas de pedra sabão devem ser curadas antes do primeiro uso, o processo de cura não é um consenso, mas todos envolvem algum tipo de óleo submetido ao calor. Quintaes (2004) salienta que foi verificado cientificamente, que o processo de cura das panelas de pedra previne a migração indesejável do níquel para o alimento. Porém a população local acredita que a cura inibe rachaduras no material durante a vida útil da panela.

Estudos nutricionais com as panelas de pedra-sabão curadas demonstram que os preparos habituais da população brasileira, como arroz branco e molhos de tomate, mostrou haver acréscimo relevante de ferro e cálcio, ambos benéficos. Os estudos revelam também que são contra indicadas para a armazenagem do alimento.

A principal vantagem da panela de pedra-sabão é que o calor propaga-se por igual em toda sua superfície, cozendo os alimentos de maneira integral e não só pelo fundo. Por ser antiaderente, não fica impregnada por resíduos de alimentos, mantendo-se livre de odores. Sua limpeza é fácil, mas prejudicada pelo seu peso, mas pode ser lavada tanto à mão como à máquina de lavar louças. Assim como faz com o 
calor, conserva também o frio, assim é ideal para cooler de vinho e champanhe, balde de gelo e pratos para sushi.

Outras características são sua durabilidade e seu aspecto decorativo, que se conservam inalteradas no tempo suas características e funcionalidades. Tradicionalmente são usados pelos chefes europeus na cozinha profissional, são, ao mesmo tempo, objetos refinados e decorativos.

Existem várias motivações para o uso da panela de pedra sabão pela população mineira, entre as quais se destacam a disponibilidade do produto, baixo custo, a manutenção da temperatura do alimento, tradição, entre outros. $\mathrm{O}$ uso regular deste utensílio é associado empiricamente pela população mineira, à prevenção e tratamento da anemia. O esteatito é constituído por ferro, cálcio, magnésio, manganês e níquel, a autora avaliou a migração desses metais, principalmente do ferro para um simulante de alimento, em duas concentrações, e obteve como resultado valores elevados destes metais, fornecendo subsídio para o conhecimento popular, embora sem ter sua biodisponibilidade determinada. Nota-se também que, o teor dos metais tende a ser maior quanto mais ácida for preparação.

Assim como mostrado na Figura 2, as principais desvantagens são: peso, fragilidade, aquecimento lento, requer tratamento de cura. Não serve para guardar alimentos, pois se o material preparado for mantido em contato com a panela, um alto teor de níquel será encontrado no alimento, o que é indesejável. Também não é indicada para fritura, devido ao envelhecimento do óleo que é otimizado pelo seu aquecimento, inutilizando-o na primeira fritura. Como vantagens, destaca-se a característica se ser naturalmente antiaderente, libera cálcio, ferro, manganês, mantém o alimento aquecido, cozinha o alimento lentamente sendo ideal para o preparo de carnes, baixo custo e fácil aquisição.

\subsection{Design e tecnologia}

A atividade do design presta sua contribuição ao intermediar as relações dos homens e os seus objetos, atribuindo significados por meio das funções dos produtos e contribuindo para a construção de identidades individuais e grupais. Para Maristela Ono (2006), o design tem como papel fundamental atender às necessidades das pessoas, traduzindo as funções requeridas por elas nos objetos, considerando sua identidade, herança e diversidade cultural.

No caso dos produtos de pedra sabão, por ser uma técnica regional, não foi possível traçar um paralelo com outras regiões do país. Contudo, o setor apresenta uma série de problemas, como o desperdício de materiais, qualidade dos produtos, mão de obra, comercialização dos produtos, entre outros. Algumas ações coordenadas estão sendo realizadas na tentativa de valorizar o produto, obter mais qualidade e redução de perdas da matéria-prima natural.

O projeto Linha de panelas de pedra-sabão para exportação realizado pelo Centro de Estudos em Design de Gemas e Joias (CEDGEM) da UEMG desenvolveu diversas linhas de produtos, embalagens e manual técnico para o fabrico das peças (Figura 3). 


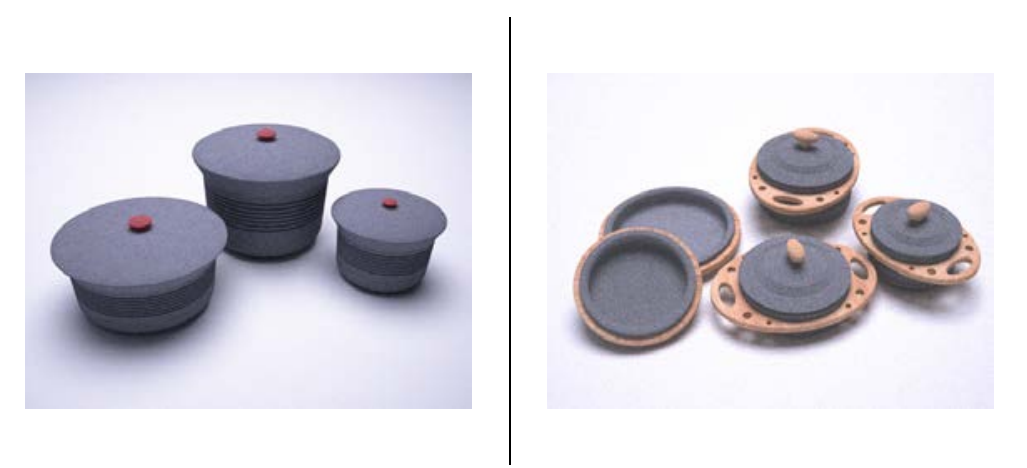

Figura 3: Design de Linhas de panelas para exportação - CEDGEM/UEMG Fonte: TEIXEIRA, OZANAN, OLIVEIRA (2008)

A maioria dos produtores de panelas de pedra é artesanal e de pequeno porte. Os modelos são praticamente os mesmos, com pequenas variações nos sistemas de pegas com diferentes materiais. Poucas empresas investem no desenvolvimento de produtos diferenciados e de maior valor agregado. A Cookstone é uma das empresas que investem no design e inovação, sendo que empresas da D. Incubadora de Empresas e Negócios de Design da UEMG desenvolveram projetos para a empresa, como mostra a Figura 4.
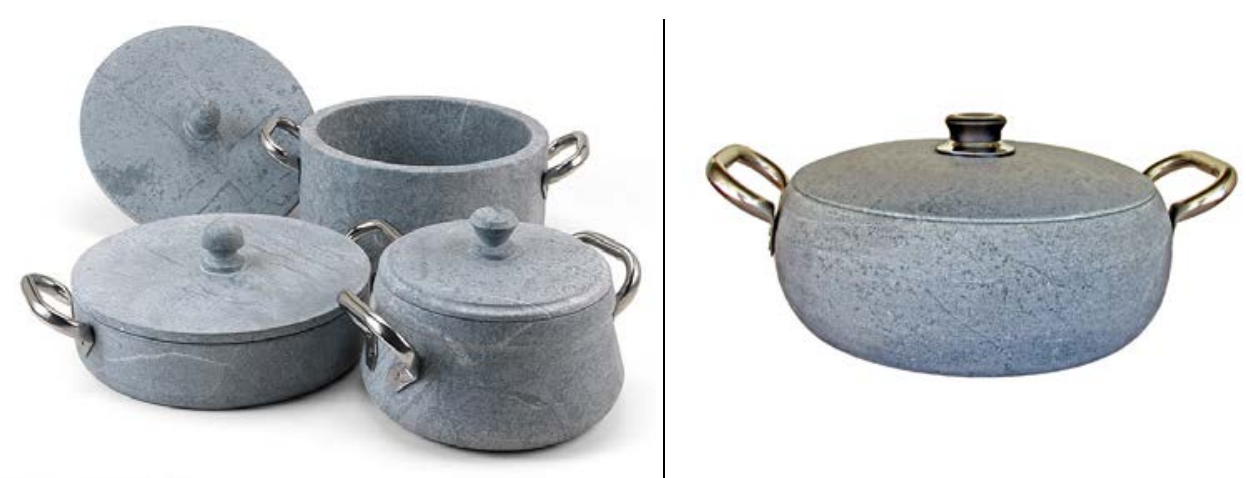

Figura 4: Produtos desenvolvidos para a empresa Artha Cookstone pela Notus Design Fonte: Notus Design

Outros diferenciais estão sendo adicionados aos produtos pelos fabricantes, destacado o fundo de metal magnético para fogões de indução (Figura 5a), uma vez que há demanda por usuários de elevado padrão de consumo. A mesma empresa, Artha Cookstone, tem investido em projetos de embalagens para o transporte das panelas (Figura 5b), de modo a obter menos quebras. Uma versão de panela de pressão foi também lançada em pedra-sabão, o que a torna bastante versátil e nesse caso ainda mais econômica em relação ao consumo de energia utilizada. 


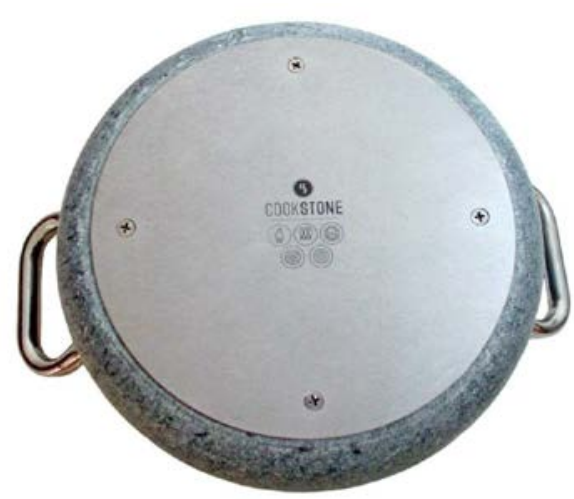

(a) Inserção de fundo metálico para fogão de indução

Figura 5: Produtos desenvolvidos para a empresa Artha Cookstone pela Notus Design Fonte: Notus Design

\subsection{Eficiência energética}

As propriedades térmicas dos materiais são conhecidas da literatura, no entanto a obtenção das propriedades térmicas do produto a partir dos materiais que os constitui não é singular. Dias (2009) analisou 11 tipos de panelas quanto a percepção do usuário em relação aos materiais utilizados para sua fabricação. Mediuse o tempo de aquecimento e tempo de resfriamento das panelas considerando um volume de dois litros de água em ebulição até retornar a temperatura ambiente. Os resultados mostram que a percepção dos usuários quanto ao material das panelas foi equivalente às mesmas panelas que tiveram igual desempenho durante o aquecimento foram as panelas de alumínio e de aço fino esmaltada e no resfriamento as de ferro fundido, aço inoxidável e pedra sabão.

Como já mencionado, a principal vantagem da panela de pedra-sabão é que o calor propaga-se por igual em toda sua superfície, cozendo os alimentos de maneira integral e não só pelo fundo. Ela é econômica, uma vez atingida a temperatura adequada, é suficiente uma chama muito baixa para mantê-la constante. Depois de aquecida, conserva por muito tempo o calor adquirido, mantendo os alimentos quentes à mesa. Permite cozinhar com pouco ou nenhum óleo, cozinhando os alimentos lentamente e de maneira integral, a pedra-sabão permite que conservem todas suas propriedades orgânicas, enquanto que o sabor e a textura são naturalmente realçados.

Uma das preocupações da equipe de pesquisa é investigar a relação existente entre a forma das panelas de pedras sabão e seu desempenho térmico. A hipótese é de que a geometria, baseado nas terminologias de contorno e forma empregados na arqueologia, pode influenciar a eficiência: contornos simples, compostos, infletido ou complexo quando variando com as formas fechadas e abertas.

A análise do desempenho térmico das panelas inicia-se com a seleção de diferentes amostras de geometrias distintas, percorre as três etapas. Na primeira se realiza uma análise teórica do desempenho térmico dos materiais de base que compõem as panelas. Ressalta-se que para este estudo tomou-se como referência as características de transferência de calor dos materiais conforme descrito na literatura clássica (Kreith, 1977). 


\section{CONSIDERAÇÕES FINAIS}

A presente pesquisa está em curso, sendo que a parte experimental, em sua segunda etapa, irá avaliar o desempenho térmico das panelas por meio da técnica da termografia infravermelha ativa. Na termografia ativa utiliza-se sistemas de excitação adicionais para promover a transferência de energia nos materiais. Uma fonte externa de calor penetra no objeto e gera gradientes de temperatura em função da espessura do sólido. Neste estudo, definiu-se por utilizar como fonte de aquecimento um fogão a gás de quatro bocas, chama comum, de uso doméstico. E por último, a avaliação do artefato em uso na atividade de cocção para avaliar aspectos perceptivos da eficiência com os usuários. O outro estudo é parte do trabalho de dissertação da aluna de mestrado, autora desse artigo, e trata exclusivamente das panelas de pedra sabão produzidas em minas Gerais, que também está em andamento.

\section{REFERÊNCIAS}

ASSOCIAÇÃO BRASILEIRA DE NORMAS TÉCNICAS. NBR14876. Utensílios domésticos metálicos - Alças, cabos, poméis e sistemas de fixação. Rio de Janeiro: ABNT, 2009.

CARDOSO, Rafael (Org.). 0 design Brasileiro antes do design: aspectos da história gráfica, 1870-1960. São Paulo: Cosac Naify, 2005.

CARDOSO, Rafael. Design, cultura material e o fetichismo dos objetos. Revista Arcos. Design, cultura material e visualidade, v. 1, número único, Rio de Janeiro, p. 14-39, out. 1998.

DE MORAES, Dijon. Análise do design brasileiro: entre mimese e mestiçagem. São Paulo: Blucher, 2006.

DIAS, M. Regina Álvares. Panelas do Brasil: aspectos da cultura material, artesanato e design. In: Oficina de design, culinária e artesanato, Florianópolis: UDESC, 2014 (no prelo).

DIAS, M. Regina Álvares. Percepção dos materiais pelos usuários: modelo de avaliação Permatus. Tese (Doutorado) Universidade Federal de Santa Catarina, Centro Tecnológico, Programa de Pós-Graduação em Engenharia e Gestão do Conhecimento, Florianópolis, 2009.

DOHMANN, Marcus (Org.). A experiência material: a cultura do objeto. Rio de Janeiro: Rio Books, 2014.

DOMINGUES, F; MORAES, Dijon de; DIAS, R. A.; Design, global products and communication: the semiotics as an epistemological foundation for the analysis of objects of use. In: Proceedings of the 6th Information Design International Conference, 5th InfoDesign, 6th CONGIC. São Paulo: Blucher, 2014, p. 868-878.

DÓRIA, Carlos Alberto. Formação da culinária brasileira: escritos sobre a cozinha izoneira. São Paulo: Editora Três Estrelas, 2014.

GIDDENS, Antony. A. Modernidade e identidade. Rio de Janeiro: Jorge Zahar, 2002.

IPHAN - Instituto do Patrimônio Histórico e Artístico Nacional. Ofício das Paneleiras de Goiabeira, Dossiê 3. Brasília, DF: Iphan, 2006. 
JUNQUEIRA, Paulo A. O grande abrigo de Santana do Riacho: abrigo com sepultamentos no Estado de Minas Gerais. 1985. Dissertação (Mestrado em Antropologia Social) - Universidade de São Paulo, 1985.

KREITH, F. Princípios de transmissão de calor. São Paulo: Blucher, 1977.

KRUCKEN, Lia. Design e território: valorização de identidades e produtos locais. São Paulo: Studio Nobel, 2009.

LEMME, Chuck. The ideal pot. In: The cooking pot: proceedings. Oxford Symposium on Food \& Cookery, 1988, pp. 82-98.

MELQUIADES, Vinicius. Fragmentos de história de vida de uma família de artefatos: as vasilhas de pedra sabão em Minas Gerais. Rev. Vestígios, v. 6, n. 2, 2012.

MELQUIADES, Vinicius. Os artesãos de pedra: arqueologia e museologia das vasilhas de pedra sabão em Minas Gerais. Dissertação (Mestrado em Arqueologia) Universidade de São Paulo - USP, São Paulo, 2011.

MELQUIADES, Vinicius. Um ofício não oficial: a produção de vasilhames de pedrasabão em Minas Gerais, séculos XVIII e XIX. In: Anais do XXVI Simpósio Nacional de História - ANPUH, São Paulo, julho 2011.

OLIVEIRA, Paulo M. Turismo, cultura e ambiente: I'approccio sistemico del design. Tese de Doutorado (Douttorato di ricerca in sistemi di produzione e design industriale) - Politecnico di Torino, Itália, 2013.

ONO, Maristela M.. Design e Cultura: sintonia essencial. Curitiba: Edição da autora, 2006.

PROUS, André. Arqueologia Brasileira. Brasília: Universidade de Brasília. 1992.

PROUS, André \& MALTA, I. M. (Coord.). Santana do Riacho - Tomo I. Arquivo do Museu de História Natural UFMG. Belo Horizonte. Vol. XII, 1991.

QUINTAES, Késia Diego. Implicações nutricionais decorrentes do uso de panelas brasileiras de aço inoxidável, ferro e pedra sabão (esteatito). Tese de Doutorado (Doutorado em Nutrição) Universidade Estadual de Campinas - Unicamp, Campinas, 2004.

QUINTAES, Késsia. Por dentro das panelas. São Paulo: Varela, 2005.

TEIXEIRA, M. B.; OZANAN, Luiz H.; OLIVEIRA, Paulo M. Projeto pedra sabão: linha de panelas de pedra sabão para exportação região de Mariana e Ouro Preto - MG.

Relatório técnico. Belo Horizonte: UEMG, 2008.

WILSON, Bee. Pense no garfo: uma história da cozinha e de como comemos. Rio de Janeiro: Zahar, 2014.

WUST, I. Continuidade e mudança: Para uma interpretação dos grupos ceramistas pré-coloniais da bacia do rio Vermelho, Mato Grosso. Tese de doutorado: São Paulo, 1990. 